\title{
Graph Description as an Issue in L2 Academic English Writing
}

\author{
Valentina Khrabrova \\ National Research University Higher School of Economics
}

\begin{abstract}
Correspondence concerning this article should be addressed to Valentina Khrabrova, National Research University Higher School of Economics, 3A, ul. Kantemirovskaya, Saint-Petersburg, Russian Federation, 194100.E-mail: stefankhrabrova@mail.ru
\end{abstract}

\begin{abstract}
Young people's interest in taking international exams such as IELTS results from student mobility and their willingness to appraise language abilities. In this paper, Academic Writing Task One of IELTS is examined. This task implies candidates comprehending graphic information and processing it in written discourse. The gap between a host of graph description tests and an insignificant number of efficient teaching methods has provided a rationale for the current study. It focuses on graph description as a cognitive, psychological and educational process and employs the analysis method in the theoretical section. Based on the action research method, drawing on 25 students' written samples, the study has quested for peculiar language problems detrimental to processing the graph description task. The data have revealed the key pillars of successful written graph presentation: the combination of all four main skills, i.e. reading, listening, writing, and speaking; skills transfer; critical thinking and writing; the appropriate use of style; graphic literacy. It is concluded that the "constant nudging" method, a skills transfer, the use of appropriate vocabulary for describing trends alongside academic functional phrases and grammar features, the analysis of mass media information with numeric data are solutions to graph description issues. The findings have implications for preparing students for IELTS.
\end{abstract}

Keywords: student mobility, graph description, skills transfer, critical writing, cognitive process

It is well-known that the International English Language Testing System (IELTS), being recognized by the Council of Europe and based on the CEFR, has merited approval in a host of countries. The reason for this is that the main goal of overall testing is appraising English language proficiency of those who intend either to study or to work in English-speaking countries. Besides, L2 learners attend training courses in order to perfect their academic skills needed for expanding career opportunities. Lastly, the European document "The Report on the Bologna Process and student mobility" (Pack, 2008, p. 5) makes it clear that 'improved command of languages is a considerable asset and one of the reasons for student mobility, and that it is important for intensive language courses to be offered to incoming students.'

This paper looks into the writing aspect of the EAP (English for Academic Purposes) course that affords groundforstudents to betrained as required by the IELTS test. At first sight, such a training process comes across as an ideal and unique set of EFL teaching methods and educational tools. However, even scrutinizing some IELTS-oriented studies cannot provide teachers with a definite answer to the question of how to teach Academic Writing Task One productively since the majority of researchers pinpoint attention upon the well-known and important elements: format, scores and band scales, tips, assessment criteria, whereas the role of cognitive processes and critical writing is disregarded.

This didactic gap accounts for the need to have a deeper insight into Academic Writing Task One (AWT1) (Yu et al, 2007), as from the cognitive perspective, it is also under-explored in the literature in comparison with Academic Writing Task Two (AWT2). It is worth noting that practical IELTS resources prevail over theoretical information, especially in the matter of AWT1: a vast number of tests, tips, samples are scattered throughout Internet websites or provided by official IELTS centers versus a very limited choice of theoretical linguistic and psychological resources. It explains a lack of both teachers' and students' knowledge of the best approaches to doing IELTS tests. (Here is a short reminder of the essence of AWT1: 'test-takers will be presented with a graph, table, chart or diagram and will be asked to describe, summarize or 
explain the information in their own words. This might involve describing and explaining data, describing the stages of a process or how something works, or describing an object or event' (British Council, 2013).

The main aim of this paper is to discuss some issues of Writing Task One (graph description) by considering them in terms of theory and practice so as to expose their integrated influence on a qualitative preparation of students for their final exam based on IELTS-related principles.

\section{Materials and Methods}

\section{Theoretical Background}

Some studies reveal that students find it useful and necessary (Lewthwaite, 2007) to take up the IELTS course as it gives them a chance to be up to the university mark: a chance of being able to sort out visual data, i.e. discern between the main and secondary facts, look for significant trends, select, classify, arrange relevant data, restate them in a concise form and be able to perform a task according to four criteria described in detail in the IELTS Guide (British Council, 2013). It must be emphasized that the course is incomparable because it is "discipline-free", i.e. designed for students who study either economics or technical sciences, or humanities. Thus, it is logical reasoning, critical and independent thinking as well as other mental abilities that are needed for doing Academic Writing Task One, not a definite level of mathematical or economic proficiency. Describing visual data deals with a quick identification and interpretation of information alongside the development of the ability to transfer skills to real-life situations. In practical terms, reading business and financial news articles in international mass media, BBC World Service, Voice of America, CNN Student News and other useful sources of information that are provided with various graphs and comments on them is the best way of acquiring new vocabulary and becoming aware of visual data.

Both students and teachers unanimously argue it is time pressure (Abela, 2001) that causes the most serious difficulties in describing visuals. The allotted time of 20 minutes given for this task has always been subject of criticism. Most researchers suggest that time should be mapped out well-mindedly, which will be discussed further in the paper. Interestingly, students themselves suppose that IELTS time limit is a helpful factor. Being neither a sword of Damocles nor an obstacle, it inures to the efficient time use. Thus, this acquired skill may become a valuable asset during the note-taking process at lectures and gives a chance of becoming pressure-resistant. Critical thinking is another noteworthy point to mention in the context of this discussion. Meaningful reading of the legend and grasping the most relevant data require the involvement of such mental activities as analysis, evaluation, synthesis, reflection, and others. In this way, students can go beyond little information given in the legend and 'will be able to generate and express multiple perspectives or, if taking one point of view, providing coherent reasons for doing so' (Lewthwaite, 2007, p. 12). Critical writing implies not only an adequate written response to social and economic problems that are presented graphically but also the overall literacy implementation.

For the time being, there has been much dispute about teaching methods that are often based only on IELTS test-books, which arouses criticism. Such instructional devices prevent teachers from creativity and turn them into "text-book slaves" (Lewthwaite, 2007, p. 14). However, it is an arguable point. Teaching practice shows that there are many examples of innovative instructional devices and a wide use of different teaching methods.

According to Crystal (2008), 'writing is very suited to the recording of facts and the communication of ideas, and to tasks of memory and learning', comments, collation, connections between variables, etc. By means of writing, information becomes intelligible and approachable. In all kinds of tasks, it is needed to resort to the use of numeric data. The University of Reading Statistical Services Centre (2000, pp. 3-4) specifies the following pillars for presenting information with numeric data:

- the information should be written presentably so that the reader or viewer may comprehend it while reading or listening; this goal is called demonstration;

- writings 'should not be used to convey more than three or four numbers; sets of numeric results should usually be presented as tables or pictures rather than included in the text', which means that all-sufficient visuals are hardly to be described verbally only;

- there is a guide to writing numbers whose provisions should be studied, e.g. 'when whole numbers (integers) are given in text, numbers less than or equal to nine should be written as words, numbers from 10 upwards should be written in digits';

- it is required to structure numeric information given in tables and highlight trends, make comparison or show relationships dealing with graphs;

- unlike visuals, the written description 'should always illuminate the most significant data';

- the way visuals are described should be 'as simple as possible while having sufficient detail to be useful and informative; and the most important points for the written description are as follows: what, where, when, the source 
of information;

- statistical information is not supposed to be given for AWT1, as it is designed for scientific analysis (The University of Reading Statistical Services Centre, 2000, p. 4).

In scientific literature much information can be found about writing, one of four main language skills, but only a few of studies deal with a synergy between them in the AWT1 process (Yu et al, 2007). To correlate the main language functions and grammar features throughout four skills, McCarter presents a list of suggested AWT1 features (see Table 1):

Table 1

Task 1: The main functions and grammar features

\begin{tabular}{ll}
\hline \multicolumn{1}{c}{ Main functions } & \multicolumn{1}{c}{ Grammar features } \\
\hline introductions & complex sentences: conjunctions \\
\hline trends & noun phrases \\
\hline overviews & singular / plural \\
\hline summarizing & tenses: Simple Present/Past/Present \\
& $\begin{array}{l}\text { Perfect/Simple Future / Future } \\
\text { Perfect }\end{array}$ \\
\hline comparison/contrast & Active vs. Passive \\
\hline paraphrasing/synonyms & verbs of rise / fall \\
\hline
\end{tabular}

Note. Retrieved from "IELTS Academic Writing and Speaking Modules - a Question of Skills Transfer", by McCarter, 2011, Manchester: British Council, p. 1.

Table 1 demonstrates all key elements that students should be aware of, in order to succeed in AWT1. Secondly, knowing exactly the requirements for doing the assignment, students will try to make it a rule to include the most relevant language features in their graph descriptions. Another advantage of the list is that it is written, corrected, amended, revised and checked by the teacher. The list offers an opportunity to classify and analyze students' mistakes by using the table. In addition, a peer review of other students' writings can be carried out in the form of special comments in the margin of the list. It is strongly recommended that such lists be used on a mandatory basis so that students may gradually get accustomed to academic writing in accordance with teachers' individual requirements.

The teacher's role implies helping students to connect different skills with the aim of making the exam preparation more rational and integrated. It is apparent that there should be no restrictions in writing and speaking. By way of illustration, McCarter (2015) shows how comparison and contrast language is taught in Task 1: 'we can elicit from the students in what other parts of the IELTS exam this language is useful; in effect, in all four skills' (McCarter, 2015, p. 4). By practicing language skills in the reading module questions, students can raise their awareness of the exam prerequisites and unveil the myth of unavoidable arduousness of IELTS writing tasks. As focusing on contrast / comparison, paraphrasing, highlighting trends, summarizing and other features are also typical of essay writing and speaking, these can be exercised in practicing Writing Task 2 and the Speaking Module. It enables students to establish the link between all main skills.

In order to encourage students to use some specific language functions such as contrast / comparison, McCarter (2015) suggests a "simple technique" by making short revision cards with different language units used for class activities: individual, pair, group, mingling. In this process, students can ask others to explain notions / ideas, to compare, to write and to read aloud. The range of such activities depends on both students' motivation and teachers' creativity.

McCarter's study (2015) clarifies that in a free conversation there are more chances for students to vary their language and create different constructions that can be incorporated in their writings. For example, students can benefit from a good knowledge of reported speech rules that they regularly use in their spoken language. If this grammar has been internalized, students will be able to paraphrase so as to avoid repetition in AWT1. The process of using other different expressions and phrases enables students to become more language-competent and inspired for further learning. As this case clearly demonstrates, at the first training stage students know a certain number of phrases but do not use them. After advancing in knowledge and acquiring/developing academic skills, passive knowledge will become active.

With regard to McCarter $(2015$, p. 3), the problem of AWT1 performance is not a set of competences but a lack of skills transfer, i.e. all language skills. The method he suggests for developing them is called "constant nudging" that implies the use of students' linguistic bundle of knowledge throughout reading, listening, writing and speaking.

Some of the students have mixed feelings about the description of different graphs and devote all energies to AWT2. At the same time, AWT1 is very important for successful performance of the whole writing task: taking into consideration a wide range of graphs and a various level of candidates' awareness and competence, researchers argue that there may be a fallacious deduction or underestimation of students' academic writing skills (Yu et al., 2007). However, neither studies nor experiments have shed any light on the extent to which a specific type of graphs may influence AWT1 results. Another recurring problem is the quantity of information given in graphs. Investigations have exposed that explanatory notations and inscriptions given in the legend enhance students' awareness of the task, while graphs with little information are linguistically complex, regardless of the participants' 
language proficiency level. Despite a variety of visuals, there are some common cognitive processes that are characteristic of graph description.

The working model of the cognitive processes for AWT1 (Yu et al., 2007, p. 19) delineates a set of skills that students need to display in the writing process. Firstly, understanding the graphic and non-graphic instructions implies the involvement of English reading abilities: studying the legend by reading it carefully within 3-5 minutes - at the beginning, and proofreading - at the end of the writing process. According to this research, this necessary and toilsome part of the whole work is often ignored. Secondly, what matters at this stage is pertinent involvement or functioning of reasoning skills that correlate a type of graph with students' graphic literacy and their background knowledge and experience. The success of written work mostly depends on the extent to which the purpose of the task is understandable and whether it corresponds to its cognitive demands. Thirdly, English writing abilities include the description of the main trends of the graph. It also means using further language functions given in the Academic Phrase Bank, in addition to those that have been presented in Table 1 , e.g. introduction/conclusion, contrast/comparison, prediction, indication of causality, signaling transition, reporting result, writing about the past, present and future, monitoring, and self-evaluating. Consequently, three main groups of working skills are required from test-takers: reading, logical reasoning, writing.

The study also stresses an impact of types of graphs on the way candidates can interpret data mentally and then record the information. The fact has been ascertained that graphic literacy is of psychological importance and contributes to a better task performance. Researchers revealed a strong influence of special preliminary preparation work, i.e. intensive training course, individual or group teacher-guided work, on the final results, and they called it "coachability" (Yu et al., 2007, p. 17). In terms of coachability, a large total sum of previously written descriptions of different type of graphs, as well as peer reviews of other students' writings are important factors that may improve their score.

What students need in order to have favorable outcomes is the appropriate style of AWT1 that implies a combination of the following elements: the use of modifiers in the form of adjectives and adverbs to show amount, emphasis, time; the use of modals and common expressions for discussing possible future trends or making predictions; refusal from informal and narrative style, repetition, grammatical errors; and proofreading (Duigu, 2001, p. 39).

\section{The EAP (English for Academic Purposes) Course}

The EAP course is designed for second-year students of the National Research University Higher School of Economics, Saint-Petersburg and is aimed at attaining the following goals:

1. development of the ELL communicative competence for using it in learning, scientific and professional activities, postgraduates supervision and economic research;

2. further development of four key academic skills that are required for passing the IELTS-related exam successfully:

- automated reading skills including rate and techniques; abilities to understand English authentic texts that contain internalized grammatical and lexical units; skimming, scanning, reading for gist, inferring;

- listening skills: students' exposure to extracts from a lecture, awareness of prediction, notetaking;

- academic writing skills: understanding the structure of academic writing tasks 1 and 2; generating ideas, processing and transferring data from graphical forms into writing; constructing paragraphs with clear statements using academic phrases in accordance with the main communicative functions;

- speaking skills are practiced in the IELTS format: Part 1, Part 2, Part 3 (Varlamova et al., 2015, p. 30).

The ultimate goal of the course is not only to reach an appropriate level of students' readiness allowing them to pass the exam in the IELTS format successfully but also upgrade their generic language skills to be used integrally. It is intended that students should acquire a wide range of lexis and grammar and get to know cultural characteristics of native English speakers. Students should be able to structure oral or written utterances logically, consistently and reasonably. They need to foreground critical thinking, i.e. seek to discover assumptions, reasons and cause-and-effect links and other abilities, promote students' autonomy by supporting their own points of view and going beyond the information given.

After completing the training course, the students sit an IELTS like test. Since all kinds of tasks are arranged in the specific format, the whole procedure encourages students to gain IELTS experience, on the one hand; on the other hand, it is a kind of a "springboard" providing a good training start and a sense of enhanced confidence in their abilities to succeed in the exam at an IELTS test center.

The basic students' book chosen for the EAP course at the Higher School of Economics is "Cambridge Objective IELTS Advanced" (Black \& Capel, 2006) that provides a wide range of theoretical and practical help: 'a distinguished book among IELTS practice materials, all in one book. It has been developed for constructive and instructive language use' (Moghaddam, 2015, p. 201). 
Besides the basic course-book, teachers are provided with other supplementary resources, for example "New Insights into IELTS” (Jakeman, McDovell, 2008), “IELTS Advantage. Writing Skills. A step-by-step Guide to a high IELTS writing score" (Brown, Richards, 2010), and "Improve Your IELTS Writing Skills"(McCarter, Whitby, 2007).

\section{Research}

The paper draws on the action research design method (ARD) which is defined as a 'small-scale investigation by teachers on specific classroom problems for the purpose of curriculum renewal and/ or professional development' (Grifee, 2012, p. 109). This method enables the researcher to reflect on the results of the students' written work and think of solutions to the problems that have been identified. It is also characterized as teacher oriented for the reason that research questions arise as a result of teachers' concerns in their own classes/groups. Secondly, being based on the problem-solving approach, the ARD method allows singling out specific issues from a definite academic environment, not from applied investigations. At the same time, the identified problem will make the teacher turn to theoretical underpinning, i.e. academic research, which is likely to contribute to teacher professional development enhancement. Thirdly, ARD is based on structured reflection which is followed by a general pattern of identifying a problem; gathering and analyzing the data; implementing the plan; analyzing the data to decide what happened. The main characteristics of the method are:

- realization within a single group or groups (called insiders);

- presence of qualitative or quantitative evidence, or both of it;

- teacher-centeredness;

- disengagement of generalization;

- classroom practice improvement (Grifee, 2012, p. 111)

25 second-year economics students, with their English proficiency ranging from A2 to B2 of CEFR (2011), were exposed to a 20-minute written assignment in the form of AWT (see Fig. 1). The writings were collected, assessed and analyzed with the aim of determining the most frequent errors. It is important to note that a priori the teacher reckoned that the students' responses would be authentic due to a simulated rigid exam-like atmosphere, with no allowances for the students, such as the use of a dictionary or any other prompts. A number of similar full-format assignments had been carried out to completion only as part of homework or as classroom tests at the end of the study modules, while in lessons, due to multitasking and strict timing, attention had been given to the instruction of how to produce graph description discourse which was followed by writing a paragraph, not the whole task. The other constituent of the investigation was a pre-test self-assessment survey (see Fig. 2) that had been conducted prior to the written work in order to compare the students' general perception of AWT 1 with their real writing performance.

\section{Task 1}

You should spend about 20 minutes on this task.

The table below shows the projected costing over the next five years in American dollars for three environmental projects for sustainable forestry. The pie chart shows the expected expenditure breakdown allocation for the first year as the projects are set up.

Summarize the information by selecting and reporting the main features, and make comparison where relevant. Write at least 150 words.

Table 2

Writing Task One: Projected costings over the next five years

\begin{tabular}{cccccc}
\hline & Year 1 & Year 2 & Year 3 & Year 4 & Year 5 \\
\hline West Africa & $\begin{array}{c}10.5 \\
\text { million }\end{array}$ & $\begin{array}{c}7.5 \\
\text { million }\end{array}$ & $\begin{array}{c}2.5 \\
\text { million }\end{array}$ & $\begin{array}{c}2.5 \\
\text { million }\end{array}$ & $\begin{array}{c}3.5 \\
\text { million }\end{array}$ \\
\hline $\begin{array}{c}\text { Central } \\
\text { America }\end{array}$ & $\begin{array}{c}20 \\
\text { million }\end{array}$ & $\begin{array}{c}12 \\
\text { million }\end{array}$ & $\begin{array}{c}5 \\
\text { million }\end{array}$ & $\begin{array}{c}5 \\
\text { million }\end{array}$ & $\begin{array}{c}5 \\
\text { million }\end{array}$ \\
\hline $\begin{array}{c}\text { South-East } \\
\text { Asia }\end{array}$ & $\begin{array}{c}30 \\
\text { million }\end{array}$ & $\begin{array}{c}20 \\
\text { million }\end{array}$ & $\begin{array}{c}40 \\
\text { million }\end{array}$ & $\begin{array}{c}50 \\
\text { million }\end{array}$ & $\begin{array}{c}50 \\
\text { million }\end{array}$ \\
\hline
\end{tabular}

Note. Reprinted from: "Improve Your IELTS Writing Skills: Student's book with answers," by S. McCarter and N. Whitby, 2007. Oxford: MacMillan Education, p. 69

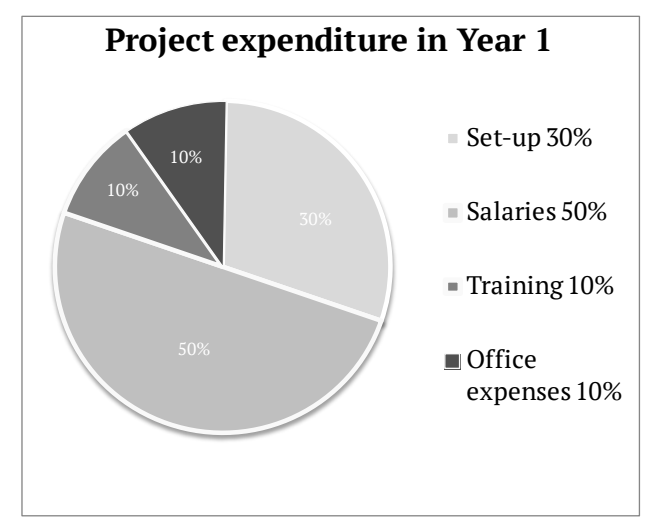

Figure 1. Writing Task One: Projected costings over the next five years (McCarter, Whitby, 2007, p. 69).

Note. Reprinted from: “Improve Your IELTS Writing Skills: Student's book with answers," by S. McCarter and N. Whitby, 2007. Oxford: MacMillan Education, p. 69. 


\section{Results and Discussion}

The participants' self-analysis has revealed the fact that the majority of economics students have no obvious difficulties in interpreting graphic data. Nor do they face serious problems when describing two graphs (in the current case - a table and a pie-chart). As is clear from Figure 2, the lack of time and the fear of making mistakes raise alarming issues in the graph description performance, which is evident from their percentage containing a high ratio of 30 each. They are followed by the lack of vocabulary/grammar issue whose proportion reaches the magnitude of 13 percent. Remarkably, the no-problem ratio is coequal to that of vocabulary and grammar. The difficulty in the interpretation of the legend aggregates 10 per cent, whereas the misapprehension issue does not exceed 4 per cent.

Relying on the ARD method in this study, we seek to answer the research questions:

1) what theoretical language problems have a negative impact on student awareness of the graph description process?

2) what practical inferences can be made in order to improve the writing results?

Table 3 concisely demonstrates the research findings based on the results of the current study: both problems and their gist. As is apparent, the difficulties are clustered in 6 blocks in the table: word-for-word strategy, repetition, wordiness, inappropriate style, limited range of vocabulary, limited range of grammar (Duigu, 2001, p. 38). In the findings, the number of blocks is reduced to two large groups as they regard comparable domains: (1) word-for-word-strategy, repetition and wordiness, (2) inappropriate style and a limited range of vocabulary/grammar.

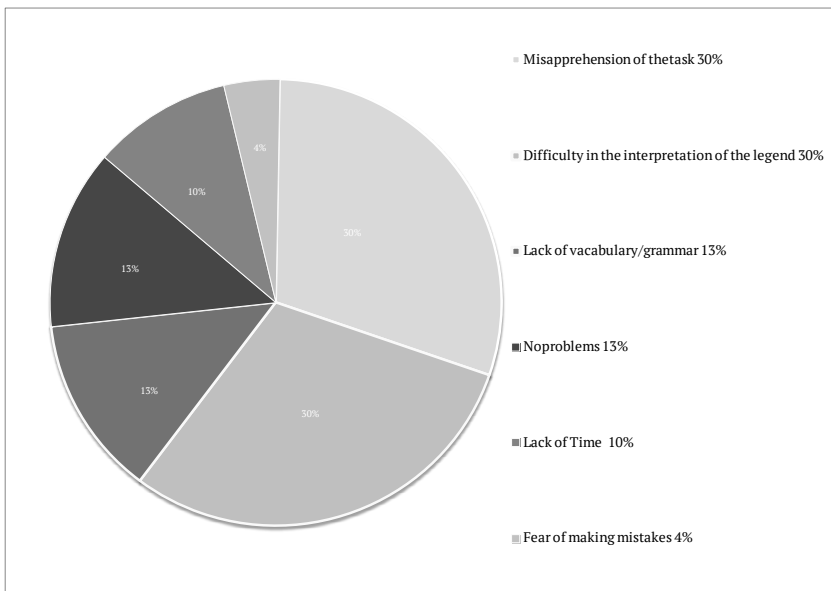

Figure 2. Results of the survey: student issues in describing graphs.
Table 3

Students' most frequent problems in graph description writing

\begin{tabular}{ll}
\hline \multicolumn{1}{c}{ Problem } & \multicolumn{1}{c}{ Exposition } \\
\hline $\begin{array}{l}\text { word-for-word } \\
\text { strategy }\end{array}$ & deriving words from the task/ legend \\
\hline repetition & $\begin{array}{l}\text { using the same words for several times } \\
\text { throughout the task, disregarding synonyms / } \\
\text { antonyms }\end{array}$ \\
\hline wordiness & employing vague and excessive language \\
\hline $\begin{array}{l}\text { inappropriate } \\
\text { style }\end{array}$ & $\begin{array}{l}\text { using the narrative essay style or an informal } \\
\text { style; presence of judgments in the first person }\end{array}$ \\
\hline $\begin{array}{l}\text { limited range } \\
\text { of vocabulary }\end{array}$ & $\begin{array}{l}\text { disregarding the main parts of speech: nouns, } \\
\text { verbs, adjectives and adverbs in order to } \\
\text { describe trends and express the movement or } \\
\text { the speed of change }\end{array}$ \\
\hline $\begin{array}{l}\text { limited range } \\
\text { of grammar }\end{array}$ & $\begin{array}{l}\text { confining the use of degrees of comparison } \\
\text { to only basic forms; confusing tenses, i.e. } \\
\text { using Present Continuous instead of Future }\end{array}$ \\
& $\begin{array}{l}\text { Indefinite; Present Simple instead of Past } \\
\text { Simple }\end{array}$ \\
\hline
\end{tabular}

The frequency of word-for-word-strategy, repetition and wordiness patterns exceeds the other problem domains. Although the students resort to them throughout their writings, the above strategies are particularly characteristic of the introductory part where it is required to paraphrase the given task, which is often ignored on account of an inability to derive appropriate words from a person's limited word stock. For example:

Student 1 (introduction): The table gives us information about the costings of the environmental projects during 5 years (see Fig. 1).

Student 2 (introduction): The sector diagram deals with the detailed expenditure allocation for the first year of project management.

As mentioned above, inappropriate style and a limited range of vocabulary/grammar have been taken jointly due to their close interdependence. The poor graph description style emerges from its confusion with the essay style for which descriptive elements are an inherent part of written discourse. Some of the most frequent errors detected during the analysis of the students' AWT1 include the following: (1) vague and excessive vocabulary; (2) unextended incoherent sentences; (3) extended sentences with narrative style elements, the use of personal pronouns; (4) the use of imperatives and colloquial language; (5) the use of the be going - construction instead of Future Simple. The following examples from the students' writings substantiate the above statements:

(1) - It's worth analyzing and summarizing the information about the projected costings over the years and the expected expenditure over first year in West Africa, Central America and South-East Asia. 
Table 4

Occurences of nouns, verbs, adjectives, adverbs for describing trends

\begin{tabular}{|c|c|c|c|c|c|c|c|}
\hline trends & $\begin{array}{c}\text { nouns/ } \\
\text { occurrences in } \\
\text { numbers }\end{array}$ & & $\begin{array}{c}\text { verbs / } \\
\text { occurrences in } \\
\text { numbers }\end{array}$ & & $\begin{array}{l}\text { adjectives/ occurrences } \\
\text { in numbers }\end{array}$ & $\begin{array}{c}\text { adverbs/ occurrence } \\
\text { numbers }\end{array}$ & \\
\hline \multirow{12}{*}{$\begin{array}{l}\text { rise, extensive } \\
\text { change }\end{array}$} & boom & 1 & grow & 5 & big, biggest & dramatically & 1 \\
\hline & increase & 3 & increase & 7 & considerable & seriously & 1 \\
\hline & growth & 3 & rise & 4 & dramatic & sharply & 1 \\
\hline & peak & 2 & & & enormous & significantly & 2 \\
\hline & & & & & great/est & totally & 1 \\
\hline & & & & & high/er/st & 5 & \\
\hline & & & & & huge/st & 4 & \\
\hline & & & & & large/er/st & 9 & \\
\hline & & & & & prominent & 1 & \\
\hline & & & & & significant & 2 & \\
\hline & & & & & substantial & 1 & \\
\hline & & & & & sufficient & 1 & \\
\hline \multirow{9}{*}{ fall, slow change } & breakdown & 3 & drop & 4 & downward & gradually & 1 \\
\hline & decline & 3 & decline & 9 & low/er/est & 3 & \\
\hline & decrease & 3 & decrease & 14 & small & 6 & \\
\hline & downturn & 1 & fall & 3 & minimal & 1 & \\
\hline & drop & 1 & diminish & 1 & slight & 1 & \\
\hline & fall & 2 & reduce & 2 & & & \\
\hline & reduction & 1 & lower & 1 & & & \\
\hline & slope & 1 & & & & & \\
\hline & slump & 1 & & & & & \\
\hline \multirow{6}{*}{$\begin{array}{l}\text { other changes/ } \\
\text { trends }\end{array}$} & & & remain + adj. & 5 & constant & approximately & 3 \\
\hline & & & fluctuate & 1 & equal & comparatively & 1 \\
\hline & & & exceed & 1 & stable & constantly & 2 \\
\hline & & & level out & 1 & sustainable & equally & 1 \\
\hline & & & reach + noun & 5 & total & relatively & 2 \\
\hline & & & & & & respectively & 6 \\
\hline total & & 25 & & 63 & & 67 & 22 \\
\hline \multicolumn{5}{|c|}{$\begin{array}{l}\text { - Overall, taking all countries into consideration, it } \\
\text { could be said that the most money requiring year will } \\
\text { be the fifth and the most part of outgoes will go on } \\
\text { salaries. } \\
\text { (2) - Salaries require half of the budget. Set-up costs } \\
\text { need 30\% of money. Each year spendings for the } \\
\text { project are different. } \\
\text { (3) - We can see that most money will be invested in } \\
\text { south-west Asia. } \\
\text { - To sum up, from these graphs we will find designed } \\
\text { costings during the period of the five years in three } \\
\text { regions. } \\
\text { (4) - This amount of money is nothing compared to } \\
\text { the enormous } 190 \text { million dollars that are projected } \\
\text { to be spent in south-east Asia. } \\
\text { - Now let's move on to the table. The total expenses } \\
\text { of West Africa project are dropping from } 10.5 \\
\text { million to } 2.5 \text { million in year } 3 \text { and year } 4 \text {. } \\
\text { (5) According to the pie chart, sixty per cent of }\end{array}$} & \multicolumn{3}{|c|}{$\begin{array}{l}\text { money is going to be spent on people (fifty per cent } \\
\text { - on their salaries and the other ten per cent - on } \\
\text { training). } \\
\text { The research draws special attention to the use } \\
\text { of parts of speech in AWT1 by means of Table } 4 \text { that } \\
\text { shows the occurrences of nouns, verbs, adjectives, } \\
\text { adverbs in the students' writings. } \\
\text { Firstly, the total numeric occurrences of nouns } \\
\text { are estimated at 25, being only } 3 \text { units larger than } \\
\text { those of adverbs. Additionally, nouns are not used for } \\
\text { describing such changes as fluctuation or stability. In } \\
\text { terms of Writing Band Descriptors Task } 1 \text {, the use of } \\
\text { nouns is adequate but insufficient. The triple use of } \\
\text { the noun breakdown and the eightfold occurrence of } \\
\text { the adjective sustainable, elicited from the task (see } \\
\text { Table } 2 \text { ), verifies the student propensity for word-for- } \\
\text { word strategy. Another obvious trend consists in the } \\
\text { ignorance of verbs to describe trends or action. Instead, } \\
\text { adjectives as parts of nominal predicates are employed }\end{array}$} \\
\hline
\end{tabular}


extensively, which is reflected on their relatively high frequency by contrast to the other parts of speech. Despite it, the qualitative range of adjectives is far from sufficient, standing at only 22 (see Fig. 3). As well as this, the number of adjectival comparatives and superlatives is limited to such commonplace words as bigger/biggest, smaller/smallest, larger/largest. All in all, the analysis of the occurrences of parts of speech provides strong evidence of a lack of vocabulary stock to describe trends, which is supported by Figures 3 and 4.

Hinkel (2004, p. 18) states that 'what students need is to become relatively good at displaying academic knowledge within the formats expected in academic discourse and text', which does not necessarily involve becoming 'proficient narrators' (Hinkel, 2004, p. 17). In compliance with this postulate, some students' writings have been regarded as successful, for example that given below (see Fig. 1):

"The given table and a pie chart diagram represent the information about the implementation of projects concerning forests. The table shows the distribution of money between the 3 parts of the world during the period of 5 years, whereas the graph demonstrates the ratio of different costs of the program in the first year. It can be easily noticed that the most considerable amount of millions of dollars is projected to be transferred to SouthEast Asia, while wage expenditures remain relatively more costly. The share of salaries constitutes half of the entire sum, being five times larger than office and training costs, which are expected to be less substantial. Set-up payments exceed both of the latter by 10 per cent. The expenses for the realization of the program in South-East Asia are predicted to rise gradually. In stark contrast to this, West Africa's and Central America's financial support of program declines during the estimated period though the expenses for Central America do not surpass America's numbers. In the beginning, Asia's disbursement stands at 10 which is much more considerable than that of Central America's and West Africa's. Ultimately, Asia's outlay has mounted tenfold".

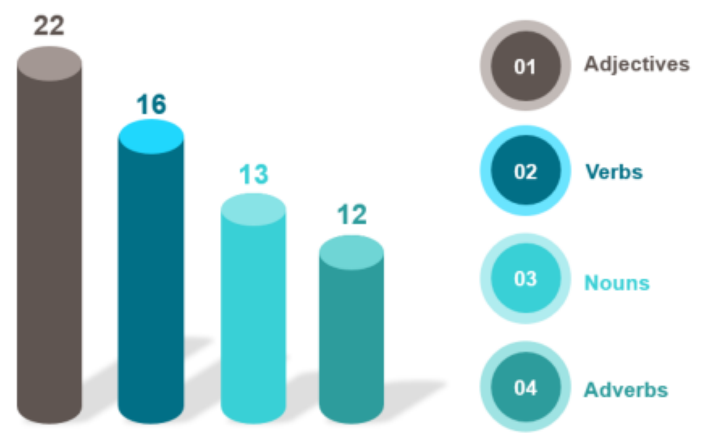

Figure 3. Qualitative comparison of the occurrences of the main parts of speech for describing trends.

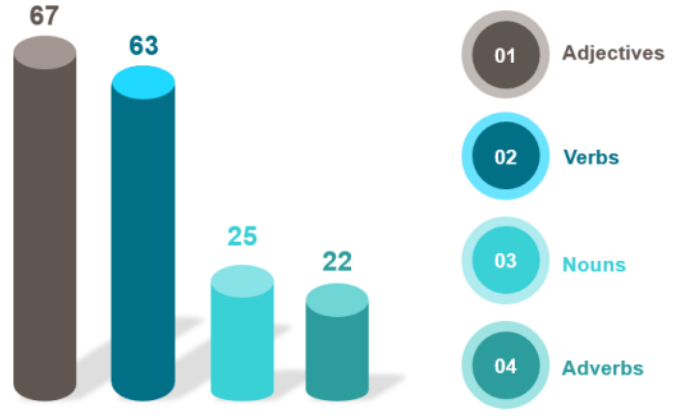

Figure 4. Quantitative comparison of the occurrences of the main parts of speech for describing trends.

\section{Conclusion}

A number of final comments appear as a result of the above arguments and the analysis presented in the theoretical section. Most significantly, academic graph description is a formal message that contains evident data and numeric information. Critical thinking and writing are consequential abilities that are needed for successful task achievement. The problem of AWT1 performance is not a set of competences but a lack of skills transfer, which requires the integrated use of all four language skills on a regular basis. According to the working model of the cognitive process, three main groups of working skills are required from L2 learners: reading, logical reasoning, writing. Provided these skills are underdeveloped and academic writing procedures are ignored, a number of language and technical issues are likely to emerge. The following writing flaws have been delineated: word-for-wordstrategy, repetition and wordiness, inappropriate style and a limited range of vocabulary/grammar. The research has revealed gaping gaps between the required use of a range of parts of speech for describing trends in the AWT 1 performance and its real poor implementation; between the students' homework results and their classroom performance. To fill in these gaps, full-format AWT 1 assignments should be carried out on a regular basis as part of classroom activities to keep track of the students' progress and elicit immediate feedback from them. It also entails pursuing the strategies aimed at solving the above issues: practicing simple techniques by means of a variety of class activities, using the "constant nudging" method, i.e. teachers' series of actions designed to accustom students to a skills transfer, using academic functional phrases and grammar features, presenting information with numeric data in a correct way.

Given a small group of students participated in the investigation, the practical findings cannot be generalized at large, having been founded on the ARD 
method established principles (see Method). Nunan (1990, p. 64) calls this characteristic a lack of rigor that prevents the data from being called truly accurate. Due to it, the research results need to be interpreted with caution until further research is accomplished in order to support the inferences by substantial data.

\section{References}

Abela, J. (2001). IELTS: The ultimate unofficial guide. New York, NY: Penguin Classics.

Black, M., \& Capel, A. (2006). Cambridge objective IELTS advanced (1st ed.). Cambridge, UK: Cambridge University Press.

British Council. (2013). IELTS guide for teachers. Retrieved from http://www.idpielts.me/wpcontent/uploads/2013/10/Guide_Teachers_2013. pdf

Brown, R., \& Richards, L. (2010). IELTS advantage. Writing skills: A step-by-step guide to a high IELTS writing score. London, UK: Delta Publishing Ltd.

Council of Europe. (2011). Common European framework of reference for languages: Learning, teaching, assessment (12 $2^{\text {th }}$ ed.). Cambridge, UK: Cambridge University Press.

Crystal, D. (1995). Speaking of writing and writing of speaking. Longman Language Review 1, 5-8.

Duigu, G. (2001). Visuals: Writing about graphs, tables and diagrams. Cammeray, Australia: Academic English Press.

Grifee, D. (2012). An introduction to second language research methods: Design and data. Berkeley, CA: TESL - EJ Publications.

Hinkel, E. (2004). Teaching academic ESL writing: Practical techniques in vocabulary and grammar. London, UK: Lawrence Erlbaum Associates.

Jakeman, V., \& McDovell, C. (2008). New insights into IELTS: Student's book with answers. Cambridge, UK: Cambridge University Press.
Lewthwaite, M. (2007). Teacher and student attitudes to IELTS writing tasks: Positive or negative washback? UGRU Journal, 5, 1-16.

McCarter, S. (2011). IELTS academic writing and speaking modules - A question of skills transfer. Manchester, UK: British Council.

McCarter, S., \& Whitby, N. (2007). Improve your IELTS writing skills: Student's book with answers. Oxford, UK: MacMillan Education.

Moghaddam, S. (2015). Cambridge objective IELTS ( $1^{\text {st }}$ ed.). Journal of Teaching English for Specific and Academic Purposes, 3, 201-203.

Nunan, D. (1990). Action research in the language classroom. Cambridge, UK: Cambridge University Press.

Pack, D. (2008). Draft report on the Bologna process and student mobility. European Parliament. Retrieved from http://ond.vlaanderen.be/hogeronderwijs/ bologna/news/archive_2008.htm

Statistical services centre. (2000). Informative presentation of tables, graphs and statistics. Reading, UK: University of Reading. Retrieved from http://www.reading.ac.uk/ssc/resources/Docs/ PresentationOfTablesGraphsAndStatistics.pdf

University of Cambridge: ESOL examinations. (n.d.). IELTS writing band descriptors: Task 1. Unpublished public version. Retrieved from http://www.ieltsexam.net/docs/Writing_Band_Descriptors.pdf

University of Manchester. (n.d.). The academic phrasebank, the University of Manchester. Retrieved from http://www.phrasebank.manchester.ac.uk/

Varlamova, Y. et al. (2015). Rabochaya programa distsipliny fakultativ angliisky yazyk dlya napravleniya economica podgotovki bakalavra [The working programme of the optional discipline "The English language" for bachelor-level students of economics]. Saint-Petersburg, Russia: HSE.

Yu, G., Rea-Dickins, P., \& Kiely, R. (2007). The cognitive processes of taking IELTS. Research Reports, 11, 6 $-21$. 